\title{
Inclusive education strategies in New Zealand, a leader in inclusive education
}

\author{
David Mitchell ${ }^{\text {1 }}$ \\ ${ }^{a}$ University of Canterbury
}

\begin{abstract}
Since 1989, the New Zealand education system has undergone extensive reforms to become one of the most devolved systems in the world. The article analyses the extent to which the educational situation in New Zealand complies with the ten features of inclusive education: vision, placement, curriculum, assessment, teaching, acceptance, access, support, resources, and leadership. This paper will briefly explain these features and illustrate them with references to the situation in New Zealand and, finally, come to the conclusion that with all of these criteria New Zealand performs at a high level.
\end{abstract}

Keywords: inclusive education, children with special developmental needs, differentiated instruction, level groups, organisation of education system, educational policy

\section{Introduction}

As I have described elsewhere (Mitchell, 2015), inclusive education is a multi-faceted concept, which involves the consideration of ten features: vision, placement, curriculum, assessment, teaching, acceptance, access, support, resources, and leadership. In this paper, these features will be briefly explained and will be illustrated with reference to the situation in New Zealand.

College of Education, Health and Human Development, University of Canterbury, Private Bag 4800, Christchurch, New Zealand; david.mitchell@canterbury.ac.nz 


\section{New Zealand: The Country}

New Zealand is a small (population 4.4 million) social democracy situated in the South Pacific. Its area places it $76^{\text {th }}$ out of 257 countries and territories - about the same size as the British Isles. It has a unicameral parliamentary government and a common law system based on the English model. Its per capita GDP places it $47^{\text {th }}$ in the world, while its unemployment rate of $5.9 \%$ ranks it in $60^{\text {th }}$ place. With a Gini index of 0.33 in 2012, New Zealand ranked $12^{\text {th }}$ out of 34 OECD countries in degree of income inequality. Its fertility rate of 2.05 is slightly above replacement level. It is a multicultural country with $71.2 \%$ European, $14.1 \%$ Maori, $11.3 \%$ Asian, 7.6\% Pacifica, $2.7 \%$ other (and 5.4\% not stated). Those professing to be Christians accounted for $45.6 \%$, Hindu $2.1 \%$, Buddhist $1.4 \%$, Islam $1.1 \%$, other $1.4 \%$, and no religion $38.5 \%$ (the total exceeds $100 \%$ as people could identify with more than one of the categories) (CIA, 2015).

\section{The New Zealand Education System}

There are three types of school in New Zealand: state schools, 'state integrated' schools, and private schools. State schools attract $85 \%$ of children. Schooling is free at these schools, although parents are asked for a contribution to help cover costs of activities that are outside of the core curriculum. 'State integrated' schools enrol just over $10 \%$ of children. They are schools with a special character - for example, they may be run by a particular religious faith (e.g. Catholic), or employ particular approaches to education (e.g. Steiner). Education in these schools is also largely funded by the government but they may charge fees for various facilities. Just under $5 \%$ of children go to private schools which charge fees but also receive about $25 \%$ of their funding from government.

Education is compulsory for all children in New Zealand aged six to 16 although most children start when they turn five. Their schooling begins at primary school. If it is a 'full' primary school, they stay there from five to 12 years old. If it's a 'contributing' primary school they will move onto to an 'intermediate' school for their last two primary school years, from 11-12 to 12-13 years-old. Secondary school extends from ages 13 to 18 . Students at primary/intermediate schools are regularly assessed against expectations for their age level as set out by the National Standards. At secondary school in their last three years, students are assessed for the National Certificate of Educational Achievement (NCEA). 
Since 1989, the New Zealand education system has undergone extensive reforms, with the result that it is one of the most devolved systems in the world. The Ministry of Education (MoE) is responsible for determining overall policies and the design of the national curriculum. The independent Education Review Office (ERO) undertakes three-yearly reviews of the quality of education provided in all 2,532 schools, as well as early childhood centres. ERO also publishes national reports on specific education topics using evidence from its reviews. All state and state-integrated schools have boards of trustees (BoTs) which are responsible for the governance of the school. BoTs are the employers of all staff in a school, are responsible for setting the school's strategic direction, and for ensuring that schools provide safe environments and quality education for all students. They are also responsible for overseeing the management of personnel, curriculum, property, finance and administration. Trustees are elected by the parent community, staff members and, in the case of schools with students above Year 9, the students. The principal is also a member of the board (Ministry of Education, 2015).

\section{Supports and Services for Learners with Special Education Needs}

As in most countries, educational provisions for children with special educational needs in New Zealand are quite complex. In brief, at the primary and secondary school levels there are two main provisions, centred on the degree of needs children have for support to manage the New Zealand Curriculum. Those with the highest level needs comprise 3\% of the school population who receive support under four programmes: (1) Ongoing and Renewable Resourcing Scheme (ORRS) (1\% of all children), (2) Behaviour Initiative, (3) Communication Initiative, and (4) School High Health Needs. Students with moderate to high level needs are supported by six programmes, including (1) Resource Teachers: Learning and Behaviour (RTLBs), (2) Special Education Grants, and (3) Moderate Physical, Hearing and Vision Support (Ministry of Education, 2010a).

\section{Evaluating Inclusive Education in New Zealand}

This section will briefly outline the criteria of inclusive education I have presented in other publications and indicate the extent to which they are met in New Zealand. 


\section{Vision}

Educators at all levels of the system are committed to the underlying philosophy of inclusive education and express a vision for inclusive education in legislation, regulations and policy documents at all levels of the education system.

New Zealand generally meets this criterion, as reflected in various official documents at the national level. For example, the Education Act (1989) provides that '...people who have special educational needs (whether because of disability or otherwise) have the same rights to enrol and receive education at state schools as people who do not.' Similarly, the Human Rights Act 1993 states that it is unlawful for an educational establishment, or the authority responsible for the control of an educational establishment, or any person concerned in the management of an educational establishment or in teaching at an educational establishment -

a. to refuse or fail to admit a person as a pupil or student; or

b. to admit a person as a pupil or a student on less favourable terms and conditions than would otherwise be made available; or

c. to deny or restrict access to any benefits or services provided by the establishment; or

d. to exclude a person as a pupil or a student or subject him or her to any other detriment, -

by reason of any of the prohibited grounds of discrimination [which includes disability].

Also of relevance is the statement in the National Education Goals that requires schools to ensure: 'Equality of educational opportunity for all New Zealanders, by identifying and removing barriers to achievement' (Ministry of Education, 2009). As well, New Zealand was one of the first countries to ratify the UN Convention on the Rights of Persons with Disabilities, which includes Article 24 with its commitment to inclusive education (United Nations, 2008).

\section{Placement}

Most scholars of inclusive education either explicitly or implicitly state that inclusion refers to the placement of all students in regular schools and classrooms, regardless of their level of ability. Most state or imply that this means that all learners with special education needs should be educated in age-appropriate classes in their neighbourhood schools, regardless of their ability. 
According to 2014 data on school enrolments in New Zealand, of the students making up the $1 \%$ categorised as having high needs, only $33.5 \%$ of them were being educated in special schools. The remaining $66.5 \%$ were placed in regular schools in special classes or regular classes (no statistics were available to show this distribution). In 2010, ERO (2010) evaluated a sample of 199 primary and 30 secondary schools, to ascertain the extent to which they were inclusive of 'students with high needs', who received funding and support through a variety of mechanisms. Approximately $50 \%$ of the surveyed schools demonstrated inclusive practices, another $30 \%$ had 'pockets of inclusion' and the remaining 20\% had few inclusive practices. Subsequently, the Government developed a policy to promote the achievement, participation, and presence of children with special education needs in every mainstream school (Ministry of Education, 2010c). In a 2014 follow-up in 152 schools, ERO found that $75 \%$ of schools were mostly inclusive, close to the Ministry of Education's (2010c) target of 80\%.

\section{Adapted Curriculum}

Elsewhere, I have argued that making appropriate adaptations or modifications to the curriculum is central to inclusive education (Mitchell, 2014). I pointed out that there should be a single curriculum that is, as far as possible, accessible to all learners, including those with special educational needs. As well it should include activities that are age-appropriate, but are pitched at a developmentally appropriate level. Since an inclusive classroom is likely to contain students who are functioning at two or three levels of the curriculum, this means that multi-level teaching will have to be employed; or, at a minimum, adaptations will have to be made to take account of the student diversity.

New Zealand has a single curriculum, in contrast with some countries which have separate curricula for mainstream students and for those with special educational needs. Of particular relevance to inclusive education, The New Zealand Curriculum includes the following as one of eight guiding principles: 'The curriculum is non-sexist, non-racist, and nondiscriminatory; it ensures that [all] students' identities, languages, abilities, and talents are recognised and affirmed and that their learning needs are addressed' (Ministry of Education, 2007, p.9). Students with 'high or very high needs' (a term preferred to 'disability') are those who have been determined to 'require intervention from specialists and/or specialist teachers for access to the New Zealand Curriculum, and/or adaptation of curriculum content' (Ministry of Education Eligibility Unit, 2004, p.3). As of 2014, these 
students comprised $1.1 \%$ of the total school population. It is envisaged that they need varying degrees of adaptation to curriculum content, ranging from total adaptation of all curriculum content to significant adaptation to most curriculum content, as specified in their Individual Education Plans.

\section{Adapted Assessment}

Just as learners with special educational needs are expected to participate and progress in the general curriculum, albeit with appropriate modifications and adaptations, so, too, are they increasingly being expected to participate in a country's national or state assessment regimes. Basically, there are two types of adjustments to nation- or state-wide assessments. Firstly, assessments with accommodations involve making changes to the assessment process, but not the essential content. Accommodations include alterations to the setting, timing, administration and types of responses in assessments. Secondly, alternate assessments are defined as assessments 'designed for the small number of students with disabilities who are unable to participate in the regular State assessment, even with appropriate accommodations' (US Department of Education, 2003, p.68699). They refer to materials collected under several circumstances, including: teacher observations, samples of students' work produced during regular classroom instruction, and standardised performance tasks.

In New Zealand, the New Zealand Qualifications Authority approves Special Assessment Conditions (SACs) to provide extra help for approved secondary students when they are being assessed for their NCEA. These fall within the assessments with accommodations category outlined above. SACs are intended to remove barriers to achievement to give students with special educational needs a fair opportunity to achieve credits, but without providing them with an unfair advantage over other candidates. Examples include the use of a reader, writer or computer; rest breaks; and Braille or enlarged print papers. Eligible students are those with a permanent or long-term medical, physical or sensory condition and/or specific learning disability that directly impacts on their ability to be assessed fairly (New Zealand Qualifications Authority, nd).

At the primary and intermediate school levels, it is assumed that most students with special education needs will be able to achieve the National Standards and that their progress and achievement will be reported in relation to those standards. However, alternate assessments may be employed for students who are funded through ORRS, and whose learning long term is likely to be limited to Level 1 of The New Zealand Curriculum. For 
this group of students, progress is assessed against the standards as part of their Individual Education Programme processes. Teachers may use a range of assessment tools and approaches, including narrative assessment and learning stories, to provide a rich picture of students' skills, strengths, and learning support needs (Ministry of Education, 2010b).

\section{Adapted Teaching}

Educators are increasingly expected to be responsible not only for helping students to achieve the best possible outcomes, but also for using the most scientifically valid methods to achieve them. Indeed, in the United States, the No Child Left Behind law requires teachers to use 'scientific, research-based programmes', defined as: '(1) grounded in theory; (2) evaluated by third parties; (3) published in peer-reviewed journals; (4) sustainable; (5) replicable in schools with diverse settings; and (6) able to demonstrate evidence of effectiveness.' In the book published in 2014 (Mitchell, 2014), I present some 27 strategies that have a substantial evidence base for improving outcomes for learners with special educational needs.

In New Zealand, my book is widely used. For example, it is prescribed for the training programme for Resource Teachers: Learning and Behaviour, based at the University of Canterbury. As well, the Ministry of Education's Iterative Best Evidence Synthesis programme informs education policy and practice (Alton-Lee, 2003; Ministry of Education, nd).

\section{Acceptance}

The education system and the school recognise the right of learners with special educational needs to be educated in general education classrooms and to receive equitable resourcing. Acceptance is not only a matter of recognising the rights of such learners, but also, ideally, that teachers and fellow students accept human diversity at a philosophical level and that they accept individuals with special educational needs socially and emotionally. It is obvious that there is widespread, but not universal, acceptance of inclusive education in New Zealand.

\section{Access}

Access is a very broad concept, ranging from access to education, access to the adapted curriculum and assessment (discussed earlier), and adequate physical access to and within classrooms. The latter is provided through such features as ramps and lifts, adapted toilets, doorways that 
are sufficiently wide to take wheelchairs, and adequate space for them to be manoeuvred in classrooms. Physical access also involves ensuring that all the elements of the indoor physical environment that may affect students' ability to learn are optimal. It involves attending to such matters as the design and arrangement of furniture, acoustics, lighting, temperature, air quality, and safety.

According to Standards New Zealand (2001), the design of buildings (including schools) 'shall be carried out by applying the principles of approachability, accessibility and usability to the overall design to ensure that people with disabilities, visitors and workers are able to enter and carry out normal activities and processes in buildings ...' (p.16). More specifically, the Ministry of Education, after consultation with the school's board and the student's caregiver, provides funding for any reasonable property modifications (for example, ramps, ablution facilities, lifts) required to provide access for students with a physical disability.

\section{Support}

Educating learners with special educational needs requires collaboration among many people - several professionals and parents in particular. Indeed, there are few areas of education that call upon so much collaboration and teamwork. This is particularly true in inclusive education where, ideally, general classroom teachers may work with various combinations of specialist teachers; paraprofessionals; special needs advisers; educational psychologists; therapists and other specialists; community agencies such as welfare services, police and advocacy groups; paraprofessionals; technology consultants; and, of course, parents.

In New Zealand, if a child has 'high or very high needs' the Ministry of Education directly funds a higher level of support for them through a range of schemes or services. These include the following: (1) the Ongoing and Reviewable Resourcing Scheme, which provides support for children with high or very high needs through additional teachers, teachers' aides, specialists and items a child might need in the classroom; (2) the Communication Service, which provides support for children who have difficulties with talking, listening and understanding language; (3) the Severe Behaviour Service, which provides support for children experiencing severe behaviour difficulties; and (4) the School High Health Needs Fund, which provides a teacher's aide for a child with a medical condition that requires special care in order for them to be able to attend school safely. As well, classroom teachers might be supported by (a) a Special Education Needs 
Coordinator (SENCO) who can work with parents and a child's teacher to develop a suitable programme for a child, and (b) teachers, teacher aides or other services and support the school buys through its Special Education Grant based on how many children it has and its decile ranking (reflecting the school's catchment SES), and (c) Resource Teachers: Learning and Behaviour employed by clusters of schools to provide classroom teachers with special teaching strategies, or to institute school-wide programmes.

\section{Resources}

Clearly, for the multi-faceted approach to inclusive education outlined in this chapter to be implemented, adequate resources must be provided. These include resources to cover the cost of buildings, equipment, transport and personnel. For the past decade or so, funding models for special education have been under review in many countries, driven by rising costs, concerns over the efficiency and equity in the use of resources, and concerns about the incentives inherent in funding formulae for contra-indicated practices.

In New Zealand, resource allocation is of two kinds. The first system involves identifying individual students who meet the Ministry of Education's criteria for the approximately $3 \%$ of students with the highest needs. The Ministry is responsible for determining the level and nature of support required by such students and for allocating the resources accordingly. An important step to facilitate inclusion was the decision taken in the late 1980s that resources should follow these students, whether they are in special or regular schools. Previously, students with high needs were generally only able to access extra resources if they were located in special schools. The second system is a population-based one in which schools receive Special Education Grants based on the number of children in the school and the socio-economic status of its catchment. It is assumed that these grants would be sufficient to cater for the extra costs of teaching students with moderate special needs.

\section{Leadership}

Creating a positive school culture, or ethos, involves developing and implementing goals for the school. These goals should reflect the shared values, beliefs, attitudes, traditions and behavioural norms of its members, particularly those who are in leadership positions. Leadership should be exercised throughout an education system: by legislators, policy-makers, school governing bodies, principals and teachers. At the school level, Carrington, Bourke \& Dharan (2012) describe leadership from the school principal as 
being 'pivotal, and involves him or her understanding, believing in and enabling staff to participate' (p.351).

In its 2014 review of inclusive practices for students with special needs in New Zealand schools, ERO (2015) noted that 'leaders of inclusive schools set high expectations for students, and ensured that staff understood their responsibility to meet the needs of all their students.' Further, in its earlier report, ERO (2010) found that the quality of leadership was more important than funding in differentiating the level of inclusiveness in schools.

\section{Conclusion}

Inclusive education is a multi-faceted concept that requires educators at all levels of their systems to attend to vision, placement, curriculum, assessment, teaching, acceptance, access, support, resources, and leadership. On all of these criteria, New Zealand performs at a high level.

\section{References}

Alton-Lee, A. (2003). Quality teaching for diverse students in schooling: Best evidence synthesis iteration (BES). Wellington: Ministry of Education. Retrieved from https://www.educationcounts.govt.nz/__data/assets/pdf_file/0019/7705/BESquality-teaching-diverse-students.pdf.

Carrington, S., Bourke, R., \& Dharan, V. (2012). Using the Index for Inclusion to develop inclusive school communities. In S. Carrington \& J. MacArthur (Eds.), Teaching in inclusive school communities (pp. 343-364). Milton: Wiley.

CIA (2015). The world factbook. Retrieved from https://www.cia.gov/library/publications/the-world-factbook/.

Education Review Office (2010). Including students with high needs. Wellington. Retrieved from http://www.ero.govt.nz/assets/Uploads/Including-Students-withHigh-Needs-2010-pdf-with-cover.pdf.

Education Review Office (2015). Inclusive practices for students with special needs in schools. Wellington. Retrieved from http://www.ero.govt.nz/assets/Uploads/Inclusive-practices-for-students-with-special-needs-in-schools.pdf.

Ministry of Education (2007). The New Zealand Curriculum. Wellington. Retrieved from http://nzcurriculum.tki.org.nz/content/download/1108/11989/file/The-NewZealand-Curriculum.pdf.

Ministry of Education (2009). The national education goals. Wellington.

Ministry of Education (2010a). Review of Special Education 2010 discussion document. Retrieved from http://workbridgeincorporated.virtuozzo.co.nz/OtherDocuments/ReviewOfSpecialEducation_17Mar10.doc.

Ministry of Education (2010b). Through different eyes. Wellington. Retrieved from http://www.throughdifferenteyes.org.nz/. 
Ministry of Education (2010c). Success for all - every school, every child: Building an inclusive education system. Wellington. Retrieved from http://www.education. govt.nz/assets/Documents/School/Inclusive-education/SuccessForAllEnglish.pdf.

Ministry of Education (2015). Education counts. Retrieved from https://www.educationcounts.govt.nz/data-services/data-collections/national/boards_of_trustees.

Ministry of Education (nd). BES (Iterative Best Evidence Synthesis) Programme What works evidence. Retrieved from https://www.educationcounts.govt.nz/topics/BES.

Ministry of Education, Eligibility Unit (2004). The Ongoing and Reviewable Resourcing Schemes guidelines. Wellington.

Mitchell, D. (2014). What really works in special and inclusive education (2nd ed.). Abingdon: Routledge.

Mitchell, D. (2015). Inclusive education is a multi-faceted concept. Center for Educational Policy Studies Journal, 5(1), 9-30.

New Zealand Qualifications Authority (nd). Special assessment conditions. Wellington: David Mitchell. Retrieved from http://www.nzqa.govt.nz/providers-partners/ assessment-and-moderation/managing-national-assessment-in-schools/specialassessment-conditions/.

Standards New Zealand (2001). Design for access and mobility - Buildings and associated facilities. Retrieved from http://www.standards.co.nz/assets/Publication-files/NZS4121-2001.pdf.

United Nations (2008). Convention on the Rights of Persons with Disabilities. New York. Retrieved from http://www.un.org/disabilities/convention/conventionfull.shtml.

U.S. Department of Education (2003). Title I - Improving the academic achievement of the disadvantaged. Final Rule, 68 Federal Registry 236. 